\title{
Multilingual islands in a monolingual sea: language choice patterns during group work
}

\section{Kathelijne Jordens, Kris Van den Branden \& Koen Van Gorp}

To cite this article: Kathelijne Jordens, Kris Van den Branden \& Koen Van Gorp (2016): Multilingual islands in a monolingual sea: language choice patterns during group work, International Journal of Bilingual Education and Bilingualism, DOI: 10.1080/13670050.2016.1220488

To link to this article: http://dx.doi.org/10.1080/13670050.2016.1220488

\section{曲 Published online: 09 Sep 2016.}

\section{Submit your article to this journal $\widetilde{ }$}

Џ Article views: 43

Q View related articles $\sqsubset$

View Crossmark data $\nearrow$ 


\title{
Multilingual islands in a monolingual sea: language choice patterns during group work
}

\author{
Kathelijne Jordens ${ }^{\mathrm{a}}$ (D), Kris Van den Branden ${ }^{\mathrm{b}}$ and Koen Van Gorp ${ }^{\mathrm{c}}$ \\ ${ }^{a}$ Centre for Language and Education, Faculty of Arts, University of Leuven, Leuven, Belgium; ${ }^{\mathrm{b}}$ Faculty of Arts, \\ University of Leuven, Leuven, Belgium; 'CeLTA, Michigan State University, East Lansing, MI, USA
}

\begin{abstract}
This study explores language choice patterns during group work of bilingual pupils (Turkish-Dutch) in two mainstream primary schools in Flanders (Belgium). In each school, a group of four children performed eight different tasks, related to different subjects of the curriculum. During task performance, they were exceptionally invited to use their mother tongue (Turkish), which ran against the rules of the monolingual school. Language choice data in these temporary 'multilingual islands in a monolingual sea' were gathered. Results indicate that Turkish was used for purposes related to task performance throughout all tasks. The results challenge the view, currently prevalent in Flemish education, that a submersion approach is the only viable option for bilingual pupils speaking a minority language.
\end{abstract}

\section{ARTICLE HISTORY}

Received 31 August 2015

Accepted 1 August 2016

\section{KEYWORDS}

Classroom discourse; minority language; language choice; mother tongue; childhood bilingualism; flexible multilingualism

\section{Introduction}

The achievement gap between ethnic minority pupils and pupils with only Dutch as a mother tongue in Flanders (the northern part of Belgium) is one of the greatest among Western European countries (OECD 2006). Many Flemish teachers have been found to routinely associate mother tongues other than Dutch (the main medium of instruction) with ethnic minority pupils' underachievement, particularly when the mother tongue is Turkish or Berber (Hirtt, Nicaise, and De Zutter 2007; Agirdag, Van Avermaet, and Van Houtte 2013). To enhance pupils' development of Dutch, the vast majority of schools adopt a Dutch-only policy, prohibiting the use of other mother tongues at school (Jaspaert and Ramaut 2000; Spotti 2008; Agirdag, Jordens, and Van Houtte 2014). Although this monolingual approach has become strictly endorsed in the vast majority of Flemish schools during the past decades, the social achievement gap has not diminished (OECD 2009). Still, only a minority of the school teams have reconsidered their current monolingual policy and explored alternative approaches in which mother tongues other than Dutch are used as a resource for learning.

This monolingual approach sharply contrasts with current trends in the literature on multilingualism in the classroom, which emphasize the advantages of validating all languages in class (Cummins 2000; Baker 2011). Using multiple languages in education is claimed to be a 'communicative and pedagogic resource in bilingual contexts, especially where pupils struggle to understand difficult subject matter whilst simultaneously learning a foreign language, one that is nominally the official medium of instruction' (Ferguson 2009, 231).

This article reports on an explorative case study that was conducted in two Flemish primary schools with a strict Dutch-only policy. Bilingual children were invited to use their mother tongue (Turkish) while performing different types of tasks during group work during regular class hours, 
but while being guided by an external teacher (the first author of this article) who did not belong to the regular staff of the school. The aim of the study was to shed light on the children's language choice patterns during the task performances.

\section{Literature}

Not only in Flanders, but also in many other regions with multilingual school populations, the use of mother tongues other than the official medium of instruction at school is a contested issue. Numerous studies describe a monolingual norm being applied in schools, in mainstream education where only one language is officially designated as the medium of instruction, but also in bilingual education systems or immersion contexts (e.g. Hornberger 2004; Cruz-Ferreira 2010; García 2011 in the US and Canada; Ncoko, Osman, and Cockcroft 2000; Ferguson 2003; Moodley 2007 in Africa; Gogolin 1997; Jaspaert and Ramaut 2000; Kroon and Sturm 2000; Creese and Martin 2003; Duarte 2011 in Europe).

However, despite the hegemony of monolingualism in many educational systems around the world, ethnographic studies show that multilingualism is hard to suppress in education. For one, pupils tend to be very creative in circumventing official language regulations and secretly using their mother tongues at school, also when the language policy of the school explicitly forbids them to do so (e.g. Jaspers 2008; Probyn 2009).

Individual teachers have been shown to react in different ways to pupils' subversive behavior. While monolingual beliefs are widespread amongst teachers (Dooly 2007; Young 2014; Pulinx, Avermaet, and Agirdag 2015), in practice, teachers often turn a blind eye to pupils' mother tongue use (Asker and Martin-Jones 2013; Van Der et al. 2015; Van Praag, Stevens, and Van Houtte 2015) or, as Jaspers (2016) remarks, mother tongue use is tolerated in the margins of official business at school.

This kind of educational practice strongly contrasts with the theoretical and research literature on dual-language teaching, two-way bilingual learning, additive language programs or other forms of bilingual support in which the use of the mother tongue as a valuable resource for learning is stressed (e.g. Martin-Jones and Saxena 2003; Creese 2004; Duarte 2011 and many others). Recently, a metaanalysis on the effectiveness of bilingual programs in Europe reported a small positive effect for bilingual over submersion programs on the academic achievement of language minority children, when their mother tongue was incorporated in regular instruction (Reljić, Ferring, and Martin 2015).

Case studies focusing on mother tongue use in task performance related to a particular subject corroborate the above-mentioned findings. Specifically in the context of language learning, a vast amount of studies report on L1 use as a cognitive resource for L2 task performance (e.g. Swain and Lapkin 2000; Gort 2012). Furthermore, case studies into pupils' performance of science and mathematics tasks report on the ways in which pupils draw on their native language to negotiate meaning and clarify complex subject matter (e.g. Reyes 2004; Moschkovich 2007; Planas and Setati 2009). In addition, some studies describe pupils' mother tongue use during the performance of more informal tasks. For example, in the 'Køge project' in Denmark (Jørgensen 2003) several studies were carried out to explore the language choice patterns of bilingual Danish-Turkish pupils in Danish mainstream education. Groups of bilingual pupils (Turkish-Danish) were taken out of the usual classroom and asked to perform nonlinguistic, creative tasks. Pupils drew on both Turkish and Danish during task performance (Karrebæk 2003; Møller, Jørgensen, and Holmen 2012).

Based on the observations of language use in the Køge project, Jørgensen (2008) describes 'polylingual practices': language users employ whatever linguistic features at their disposal to achieve communicative aims. Similarly, Creese and Blackledge, in the context of complementary schools, report how bilingual teachers and pupils used 'whatever signs and forms they had at their disposal to connect with one another, indexing disparate allegiances and knowledges and creating new ones' $(2010,112)$. Blackledge and Creese (2010) use the term 'flexible multilingualism' to refer to these fluid and flexible communicative practices of multilingual speakers. Also in the context of complementary school, Bonacina and Gafaranga (2011) propose the term 'medium of classroom interaction', defined 
as 'the linguistic code that classroom participants actually orient to while talking, as opposed to the policy-prescribed medium of instruction'. They, also, observed how pupils resort to their full linguistic repertoire to attain communicative goals related to task performance.

Overall, in the recent literature, there is a clear move from an approach that hinges on separating different languages in classrooms to the more concurrent and integrated use of two or more languages (Baker 2011). This implies a move from a coordinate view of bilingualism requiring the native-like control of two languages toward compound bilingualism, with two languages forming a single composite system (Gort 2012). Scholars in different educational settings report on the flexible language practices of bilingual pupils which are brought into the classroom, fulfilling a whole range of communicative goals (e.g. Reyes 2004; Bonacina and Gafaranga 2011; Creese and Blackledge 2011; Gort 2012).

The vast majority of the above-mentioned studies were conducted in educational settings in which the mother tongue is officially recognized as a medium of instruction and is used and spoken by regular teachers. This cannot be realized in the vast majority of primary schools in Flanders, where the only official medium of instruction is Dutch. The great number of mother tongues within the same classroom and the lack of bilingual teachers make it hard to integrate any type of bilingual support in mainstream education. Nevertheless, in Flanders as much as elsewhere, pupils sharing the same mother tongue circumvent official language regulations and use the mother tongue even though its use is prohibited (Jaspers 2016).

The current study therefore aims to explore mother tongue use during task performance without invasive changes in the regular, mainstream educational setting: no mother tongue courses, materials or bilingual teachers were required. A 'multilingual space' was installed in a separate classroom, in which multilingual pupils were informed to use their mother tongue, while being guided by the first author of the study. This space was labeled a 'multilingual island' as the activities took place out of the pupils' regular classroom, and were run in parallel with the regular lessons, to allow the regular teachers to stick to business as usual. In this particular setting, the language choice patterns of Turkish-Dutch bilingual pupils were explored while they performed tasks which were related to the different subjects of the school curriculum.

\section{Method}

\section{Setting}

The study focuses on pupils in Flemish primary schools with a Turkish immigrant background. These pupils are of particular interest in the Flemish educational context for two reasons. Firstly, the pupils of Turkish origin constitute a relatively large minority group in Flanders, and they have been shown to actively maintain their mother tongue and culture (Leman 1997; Yagmur 2009). Secondly, on average, the academic achievement of pupils with a Turkish mother tongue background is poorer than other immigrant pupils (Verhaeghe, Knipprath, and Mertens 2007; Belfi et al. 2011). Many teachers tend to perceive the mother tongue of Turkish pupils as one of the major causes of their academic underachievement (Agirdag, Jordens, and Van Houtte 2014).

Data were collected in two Dutch-medium primary schools located in Limburg, a region with a high concentration of pupils with an immigrant background, of which the vast majority is from Turkish origin. In both schools (called 'green' and 'blue'), this was reflected in a school population with more than $60 \%$ pupils speaking a mother tongue other than Dutch (mostly Turkish). At the time of the data collection (2013-2014), both schools had a strict Dutch-only policy, compelling pupils to use Dutch in class and at the playground at all times. The reluctance of both school teams to tolerate mother tongue use is illustrated by the fact that they agreed to cooperate with this study only under strict conditions, namely that the use of mother tongue (Turkish) would be restricted to the periods of data collection, during which a group of four pupils was pulled out of the regular classroom to work with the researcher as a guest teacher. So, to comply with the 
school teams' demands and carry out the study, 'multilingual islands in the monolingual sea' were created: while the prevailing monolingual school policy remained unchanged, the two groups of four focus pupils were invited to use Turkish during the activities the first author of this study organized in a separate classroom for the purpose of data collection.

\section{Participants}

In each school, two girls and two boys (aged 9-12) participated in eight group work sessions, spread over 1.5 years (while they were in grades 4 and 5). They were chosen randomly out of the list of all children who had indicated in a questionnaire that they used Turkish at home with at least one of their parents. Informed consent of the school team and the parents was obtained.

All participants were born in Belgium, except for Melisa (blue group) who moved to Belgium when she was three years old. Since all participants had attended a Flemish, Dutch-only school for about seven years at the start of data collection, they can be considered emergent bilinguals. All pupils had a similar socio-economic background; their parents were either unskilled blue-collar workers or unemployed, and therefore are representative of the vast majority of Belgians with a Turkish immigrant background.

\section{Data collection}

This study focuses on the pupils' mother tongue use during their performance of tasks which were related to the different subjects in the school curriculum. The major aim of the study is to explore whether the pupils would make use of their mother tongue in this particular context. Therefore, the official curriculum of Flemish primary education was analyzed in advance, and interviews with the pupils were conducted to find out what they considered to be typical school content. To explore bilingual pupils' language choice patterns during group work, eight different tasks were designed.

(1) 'Dino'. Task 1 was a science task with an information-gap eliciting discussion. The goal of the task was to find out which of four different texts contained the most plausible hypothesis for the extinction of dinosaurs. The four pupils had to discuss the different options, reach a consensus and present their conclusion to the 'multilingual camera'. Detailed task instructions were provided on paper.

(2) 'The game'. In task 2, pupils were challenged to a game on the playground. During the game two dyads of pupils had to develop strategies to capture the hidden dinosaur eggs of the other dyad. They had to put down cards on a game board, which was drawn on the playground. Dyads had to discuss in pairs where to hide their eggs and where to put a pitfall. They played the game several times with different partners. After each round, they were challenged to add or change the rules of the game.

(3) 'Kami 1'. The third task was more language-oriented: the groups of four were asked to write a story, based on pictures of a kamishibai (storytelling theatre). They chose one out of three picture sets and were asked to write a story that they were going to narrate to a class of preschool children during the next lesson.

(4) 'Kami 2'. During the performance of task 4, we went to visit the preschool classes, to tell the story written during the previous task performance. As storytellers the pupils stood behind the kamishibai and they could read out loud their story written in task 3.

(5) 'Vulcano'. Pupils were asked to design a volcano out of clay during task performance 5, a construction exercise. Materials were provided to decorate the volcano, but they were not sufficient for every pupil to work individually forcing them to cooperate.

(6) 'Bubbles'. In task 6, scientific experiments exploring 'bubbles' were carried out. Pupils observed sparkling water, described what happened when raisins were dropped in sparkling water and 
studied the effect of baking powder in still water. In the final experiment, they had the volcano (made in task 5) erupting. The pupils had to make notes about their observations and hypotheses, in order to present the experiments to the camera.

(7) 'Measuring trees'. In task 7, a mathematics task, we went outside, on the playground to measure trees using a triangle made of carton. First, pupils had to estimate the height of a particular tree. Then, a step-by-step explanation was followed while measuring the tree. Finally, they filled out a form to report their findings.

(8) 'Turkish class'. In task 8, a language awareness task, the groups designed a Turkish as a foreign language class for the researcher. The pupils had to cooperate during the preparation of the Turkish class, to make sure there would not be any overlap between their courses.

Thus, of the eight tasks, three were related to language learning and three were related to science/ mathematics. Two tasks were related to gym and crafts. As for the latter, the teachers as well as the pupils formulated the claim in interviews conducted before the onset of the data collection that more Turkish would be used during those more informal activities.

In line with Flemish educational practices, all the handouts with instructions and guiding questions were designed in Dutch only, as were my oral instructions. This was genuine because I spoke no Turkish, much like the vast majority of Flemish teachers. Pupils were informed explicitly, however, that they could use Turkish while performing the task. As such, the medium of interaction was potentially multilingual, while the medium of instruction was monolingual, Dutch (Bonacina and Gafaranga 2011).

Both groups of four carried out the eight tasks. I pulled pupils out of their regular class and took them to another classroom where the five of us were sitting around a table. Two cameras were installed to have maximum coverage of the children's verbal and non-verbal behavior. In a first phase, pupils were invited to use Turkish during data collection, which was exceptional, as the pupils had been prohibited to use Turkish at school for six years. They were also invited to teach me a few words or expressions in Turkish or talk about Turkish habits before each task performance. The cameras were introduced as being 'multilingual', understanding whichever language the children would use. In a second phase, instructions were given in Dutch about the task they were to perform. Moreover, we went through the 'agreement card' stating (1) they would work together, (2) they could only call for my help when they were completely stuck and (3) any language could be used throughout the activity. Next, the actual task performance took place. During this phase, I was not sitting with them at the same table anymore, but I was reading behind the teacher's desk. However, I was always present in the classroom. I did not interrupt their interaction, but when they asked for help I tried to support them and only intervened when their noise disturbed the neighboring class. As the pupils were not used to doing group work, they called for my help quite often. In most cases, they got stuck in their negotiation, not being able to settle disputes and disagreements. As such, the vast majority of my support took the shape of calming them down and offering them help to solve the task, for example, by providing feedback and asking guiding questions. For some tasks we went outside. I accompanied them, but tried not to interfere with their actual task performance. To be able to triangulate the observations of language choice patterns, pupils were interviewed (in Dutch) after each task performance.

Each separate task performance (introductory talks and interviews afterwards excluded) took about one hour.

\section{Data analysis}

All videotapes were transcribed verbatim. A native bilingual speaker (Turkish-Dutch) transcribed all utterances in Turkish and provided translations to Dutch. For the analysis of language choice patterns, only the corpus of phase 3 (the task performance itself) was used. Stretches of interaction in 
which I was involved (all in Dutch) were included, because they constituted an integral part of the task performance and reflect the presence of a Dutch-only teacher in a Flemish school context.

The smallest unit of analysis was the 'conversational turn', defined as the utterance or sequences of utterances (words one speaker utters) until a speaker stops or is interrupted (Sacks, Schegloff, and Jefferson 1974). Every turn in the transcript was coded as follows:

- Turkish only: all words in one turn were spoken in Turkish (inclusively frequently used loanwords).

- Dutch only: all words in one turn were spoken in Dutch (inclusively frequently used loanwords).

- Both Turkish and Dutch: at least one word was spoken in either Dutch or Turkish, the other words in the other language.

- Other: this miscellaneous category contained turns consisting of merely a name (e.g. 'Ali!') or a one-word exclamation (e.g. 'Ooh!') or turns with at least one word spoken in another language than Dutch or Turkish (e.g. 'Shit! Dat gaat niet!' [This doesn't work!] in which 'Shit!' is uttered in English and the rest of the turn in Dutch). Each of these subcategories accounted for about $1 \%$ of the data.

- Unintelligible: none of the transcribers could understand the whole turn.

This preliminary analysis showed that Turkish was used in every task performance in both groups, albeit to different extent. Based on the turn-by-turn analysis of languages used, a more detailed discourse analysis was carried out by the first author and a research assistant, to explore language choice patterns across the tasks. Because the focus of the study was on mother tongue use by exception, we focused on the stretches of the interaction in which Turkish occurred (whether intertwined with Dutch or not). During the analysis, we were particularly interested in how pupils obtained communicative aims drawing on their linguistic repertoire.

Our interpretation was not solely based on transcriptions, but video recordings were watched carefully to take into account non-verbal communication, and field notes as well as interview data were incorporated for triangulation of the data.

The excerpts presented in the findings were selected as 'telling cases' (Mitchell 1984) to exemplify multilingual practices that occurred. The selection was discussed with both the research assistant and the transcriber. Both of them confirmed that the excerpts are representative for communicative practices that we found in the transcripts. As similar examples could be found in both groups, telling episodes were chosen from transcripts of different task performances to represent the different subjects and tasks involved in the study.

\section{Findings}

First, similarities between tasks are presented, then, language choice patterns in each category of tasks are discussed and illustrated with excerpts from performances.

\section{Similarities between tasks}

There were three striking similarities in the language choice patterns between the tasks. First, in every performance of both groups, a medium of classroom interaction (Bonacina and Gafaranga 2011) combining Dutch and Turkish was used. This language use showed characteristics of 'flexible multilingualism' (Creese and Blackledge 2011) combining languages in a fluid way. The pupils showed 'polylingual' practices (Jørgensen 2008), combining features out of their whole linguistic repertoire to obtain communicative aims, as illustrated in the excerpts below.

Second, Dutch was spoken every time I was interacting with the pupils: they always switched to Dutch immediately and spontaneously when I joined the conversation. There was no single instance in which I had to ask them to address me in Dutch. 
Third, pupils in both groups presented the task outcome spontaneously in Dutch to the camera, even though it had been labeled 'multilingual'. Pupils did talk Turkish to the camera, however, to joke and sing or to address a Turkish-speaking colleague I told them about.

\section{Informal tasks}

Two informal tasks were included (related to gym and crafts). Before the task performance, the pupils told me in the interviews that this kind of more informal task was inviting to talk more Turkish, albeit secretly ('when the teacher is not too near'). Indeed, in task 5, in which pupils had to clay a volcano, in both groups, pupils used Turkish during this task performance for on-task purposes and to discuss off-task matters as illustrated in the excerpts below. In excerpt 1, Ali explained to Kerem how they could work together while claying the volcano.

Spoken in Dutch - spoken in Turkish - (translation in underneath)

Excerpt 1 (task 5 - blue group)

Ali: Yarı yarı yapalım. Sen biraz döndür, ben biraz döndürim, sen biraz döndür, ben biraz döndürim. Let's do it fifty-fifty. You turn a little, I turn a little, you turn a little, I turn a little.

A lot of quarreling was going on, mostly about sharing and dividing the materials and about who constructed the most beautiful volcano. During the construction activity, however, other topics were addressed which were not task related, like the benefits of having a dog, the divorce of a peer's parents, smoking or, as illustrated in excerpt 2, my outfit. Melisa had asked me where I got my dress and I answered, truthfully, I bought it in a second-hand shop. They considered that as very weird.

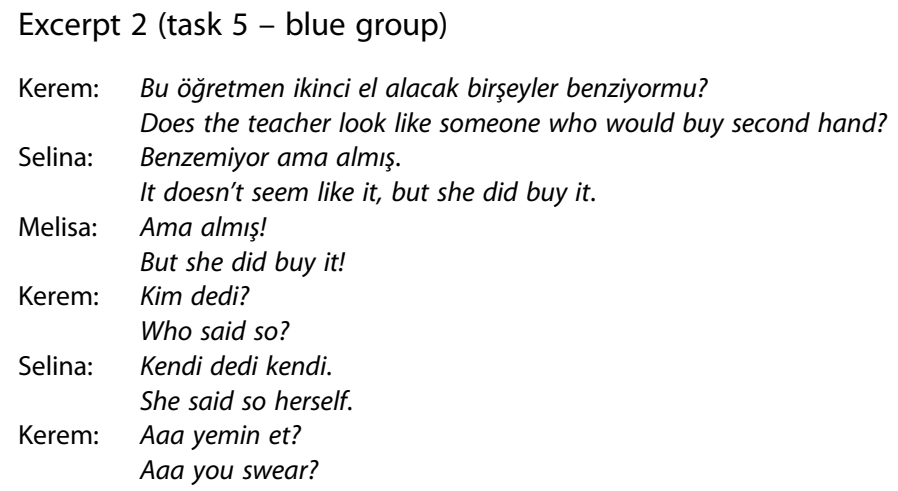

Similar episodes, in which pupils discussed my marital status, my life, my age and so on, were produced during other tasks as well.

In the other informal task (the game), Turkish was spoken much less in both groups; it was mostly used for on-task purposes. For example, in excerpt 3, Ozan and Mira were discussing their strategy to place cards on the board. Their goal was to hide the 'egg card' from the other pair and to position the 'pitfall card' in such a way that the other pair was likely to be trapped.

Excerpt 3 (task 2 - green group)

Ozan: Yumurtaları buraya koyuyorum.Vallarıda buraya koyalım.

I put the eggs here. And let's put the pitfalls here.

Mira: Ya biz düşersek?

And what if we fall in?

Ozan: Biz burdan başlarız, biz biliyoruz burda oluduğunu.

We'll start from there [points to the other side of the playboard], we know that it's here.

The word 'vallarida' is a neologism created by Ozan. While he taught me at the beginning of the game the Turkish word for 'pitfall' (tuzak), he used the Dutch stem 'val' in excerpt 3 and applied Turkish grammatical rules for declension to the stem (-lar to express the plural, $-\mathrm{I}$ for accusative 
and suffix -da meaning 'and'). So even though he knew the word in Turkish, he used the Dutch stem during the performance of the task. Similar examples of codemixing can be found in the transcripts of other groups and tasks (see also excerpt 5).

\section{The science- and mathematics-related tasks}

In the tasks related to science and mathematics, pupils mainly used Dutch, and switched to Turkish only occasionally. For example, in excerpt 4, Nuran and Mira were organizing their measurement of a tree (which was the goal of task 7). Nuran read out loud the instruction in Dutch and then proposed to go to the tree in Turkish. Mira had another plan to solve the task.

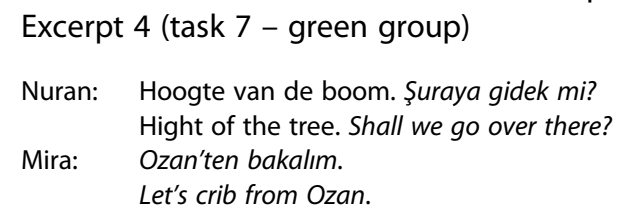

In excerpt 5, Selina tried to explain that the average between her estimation of the height of the tree and Kerem's was the actual length of the tree. She drew Dutch terminology from the task instructions and applied Turkish grammatical rules to the Dutch word stems. This way, she shows 'polylingual language use' (Jørgensen 2008), combining features out of her linguistic repertoire.

Excerpt 5 (task 7 - blue group)

Selina: Ey bizim schattingin, Kerem ve benim schattingin gemiddeldesi zaten bu boomun mete, euh, meeti işte lengtesiymis.

Of our estimations, the average of the estimation of Kerem and myself was all the measuring of the tree, eh, the measure seems to be the length.

Kerem: He o kadar akıllıymışız.

Yes, we appear to be so smart.

Selina: Ja iyi schatting yapmışı.

Yes we made a good estimation.

The excerpt vividly illustrates the ways in which pupils used Dutch words to fill gaps in their Turkish linguistic repertoire, mostly to verbalize school-related, academic ideas, which call for 'cognitive academic language proficiency - CALP' (Cummins 1979). However, they also intermingled Dutch words in Turkish speech, when they clearly knew the Turkish translation. For example, the 'pitfall' in excerpt 3, or 'tree' used in Dutch in excerpt 5, but in Turkish (ağaç) in expert 8. In the case of 'pitfall' and 'tree', the words were mostly used in Dutch, when pupils referred to the task instructions provided in Dutch. In a similar vein, they did most of the counting in Dutch, while the transcripts showed they were perfectly capable of counting in Turkish. However, Turkish also served the purpose of explaining the meaning of a Dutch word to each other, as shown in excerpt 6.

Excerpt 6 (task 6 - green group)

Doğukan: Wat denk je dat er gebeurt als je rozijnen in het glas doet? [reads out loud from instruction card] What do you think would happen if you pour raisins into the glass?

Mira: Wat is rozijnen? What is raisins?

Doğukan: Daar komen meer ... Rozijnen dat zijn hani böyle kurumuş şey oluyor ya. There's more ... Raisins, those are like something dried or so, you know.

\section{The language-related tasks}

In task 3 (writing of a story in the languages of their own choice), the blue group decided to write a story in Turkish, whereas the green group wrote a Dutch story. However, to narrate their stories written during task 3 , the green group stuck to its original language choice and told the story in 
Dutch as planned. The blue group, however, started telling the story in Turkish, as prepared, but then changed to telling the story in Dutch when they noticed that not every toddler understood Turkish.

In the transcripts of the blue group telling the story, there is no explicit discussion between pupils about whether to switch or not, they just did so. Afterwards, the pupils from the blue group told me that they made this choice deliberately. This is illustrated in excerpt 7 in which Melisa is quoted; her peers gave a very similar explanation.

Excerpt 7 - interview after task 4 (blue group)

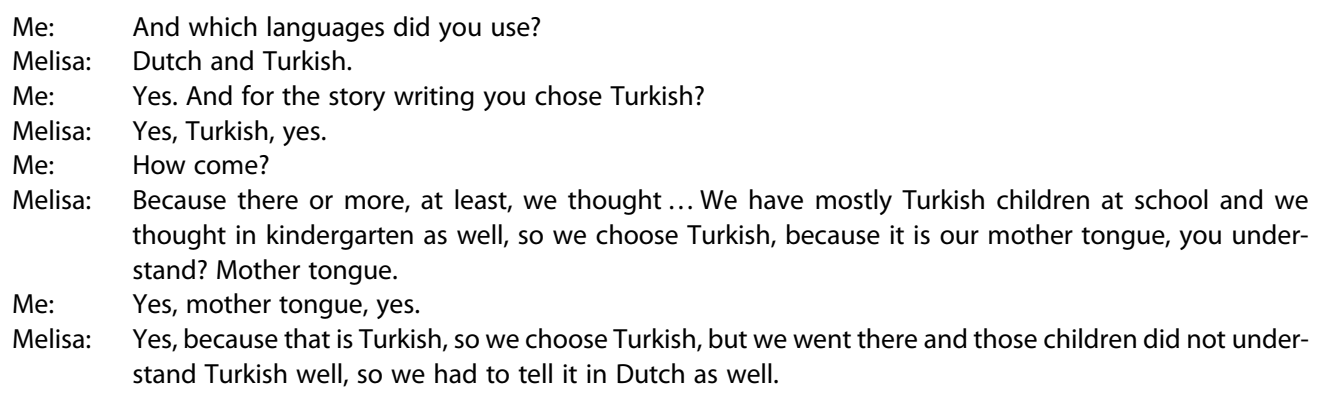

Melisa: Yes, because that is Turkish, so we choose Turkish, but we went there and those children did not understand Turkish well, so we had to tell it in Dutch as well.

The green group, too, took the needs of their audience into consideration. When I asked them why their story was told in Dutch, they answered: 'But Miss, there are only a few Turks [in kindergarten]! We had to do it in Dutch!'. This excerpt indicates that the pupils in the green group deliberately decided to tell the story in Dutch to make sure every toddler would understand.

In task 8, pupils designed a Turkish lesson for me. During this task, utterances like 'One two three is bir iki uç' were common in the transcripts of this task performance in both groups. As exemplified in excerpt 8 , Turkish was used also while the pupils were discussing the design of the course. In this excerpt, the green group was brainstorming about what they should teach me. Similar examples could be found in the blue group.

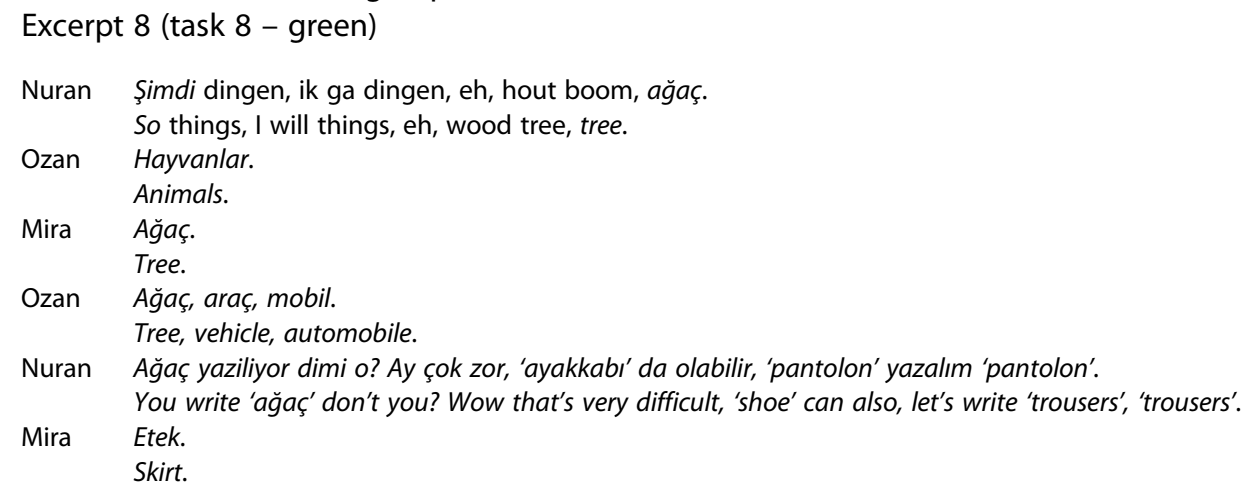

In all of the task performances, the pupils used Dutch as the default language, intermingled with Turkish. This was the case even when Turkish was of particular importance (like for the blue group writing a story in Turkish or for both groups teaching me Turkish in task 8). This observation is in line with findings of Gort (2012) who also reported pupils' predominant use of the majority language, even during a writing workshop in the minority language.

\section{Discussion}

This study was conducted in a setting we termed 'multilingual islands in the monolingual sea': multilingual practices were exceptionally invited during group work guided by an external guest teacher, deviating from the monolingual language policy regulations of the school. Before the intervention, the pupils circumvented the language regulations secretly and in the margin of official school activity. Our intervention was an attempt to bring multilingual language use out into the open. 
The results of our study show that the pupils did seize the opportunity to draw on their Turkish language skills during task performance, as shown in the excerpts that illustrate the language choice patterns in different tasks.

When carrying out the tasks, the pupils tended to recruit all elements in their linguistic repertoire, and showed that they had developed extensive multilingual skills. They switched fluently, drawing on their multilingual resources. When communicating with each other, this led to a flexible mix of language codes, which appears to be a very natural way of communicating for bilingual children (Romaine 1995; Zentella 1997). During task performance, the pupils resorted to 'flexible multilingual practices' (Blackledge and Creese 2010) and 'polylingual language use' (Jørgensen 2008).

At the same time, they appeared to be able to separate the different languages when considered appropriate, making choices which fitted the needs of their interlocutor(s) and the task at hand. Those findings are in line with Møller, Jørgensen, and Holmen (2012) who report that pupils adjust their code choice according to the situation and the other participants' skills and expectations. This use of linguistic resources in both separate and flexible ways is in line with observations of Creese and Blackledge, who report how students 'simultaneously lived both "separate" and "flexible" positions and navigated between them interactively and discursively' (2011, 1196). This language behavior was observed during the task performances in both groups.

The mother tongue was used for basic interpersonal communication, for instance for talking about personal matters or chitchatting, which they managed to do very fluently in their mother tongue. Moreover, they resorted to Turkish for task management and content-related talk, for which they needed to switch to a more cognitively demanding academic register. This is remarkable, as the pupils were not trained to use their mother tongue to discuss academic tasks. As a result, the limits of their Turkish cognitive academic language skills became apparent (e.g. excerpt 5).

The results of this study corroborate that the bilingual pupils' mother tongue use may serve social and pedagogical purposes. As such, for teachers and educational policy-makers in Flanders, it might be worth reconsidering the monolingual policy, and encouraging bilingual pupils to draw on their full linguistic repertoire during task performance. In the absence of bilingual teachers, alternative ways of supporting these pupils' development of academic language skills in the mother tongue should be considered. However, the results of this exploratory case study cannot be extrapolated to other settings, particularly those in which children are not taken out of their regular classrooms and guided by an external teacher. When multilingual practices would be implemented in the usual class, potentially language choice patterns might differ drastically from the patterns on the islands. Planas and Setati (2009) found extensive mother tongue use when pupils were working in small groups. In full class, however, they resorted to the majority language and medium of instruction or even remained silent.

In this respect, Lucas, Villegas, and Freedson-Gonzalez (2008) propose a 'linguistic responsive climate' in which pupils can support each other in their native language. In a similar vein, Sierens and Van Avermaet (2014) propose 'facilitating functional multilingual learning' as a strategy for responding to linguistic diversity at school: bilingual pupils help each other during independent group work. In this particular setting, there is no need to alter the curriculum or to employ bilingual teachers, so this way of working can be implemented in every class with at least two pupils sharing the same mother tongue. In classes with a great number of different mother tongues, parents can be invited to cooperate in class (e.g. Hélot and Young 2002), or a multilingual digital learning environment can provide learners with the advantages of bilingual learning (Van Laere, Aesaert, and van Braak 2014)

\section{Conclusion}

In many educational settings around the world, teachers seem to put a lot of effort in 'silencing linguistic diversity' (Pulinx et al 2015). Pupils, on the other hand, put lots of energy in circumventing school regulations and use their mother tongue nevertheless. All this energy might be used much 
more efficiently by taking full advantage of pupils' multilingual repertoires as resources for task performance.

This study aimed to explore the language choice patterns of multilingual pupils for whom the use of the mother tongue during regular classroom activity was prohibited. When invited to use their mother tongue by exception, the pupils drew on their full linguistic repertoire to perform schoolrelated, cognitively demanding tasks, including science, mathematics and language learning tasks, and also for playing and crafting.

This study shows it might be time for teachers to dive into a (more) multilingual sea. As Nuran puts it 'If you don't get something in Dutch and then you change to Turkish, and then you can understand, well yes, with two languages it is easier. So that's better hey.' Her claim is at odds with the current one-language-only approach at school. This study indicates that it might be time to stir up the monolingual norm, not only in the margins, but in official school activity as well.

\section{Acknowledgements}

We would like to extend our sincere appreciation to the anonymous reviewers whose feedback helped improve the quality of this paper. Many thanks also to Orhan Agirdag and Lore Van Praag for their useful comments on an earlier version of this paper.

\section{Disclosure statement}

No potential conflict of interest was reported by the authors.

\section{Funding}

This work was supported by the Agency for Innovation by Science and Technology (IWT), Flanders (Belgium) [grant number 110008] (Valorizing Linguistic Diversity in Multiple Contexts of Primary Education 'Validiv').

\section{Notes on contributors}

Kathelijne Jordens is a Ph.D.-researcher at the Centre for Language and Education, at the Faculty of Arts of the University of Leuven.

Kris Van den Branden is a teacher trainer and a professor of linguistics (language policy, language education) at the Faculty of Arts of the University of Leuven.

Koen Van Gorp is Head of Foreign Language Assessment at the Center for Language Teaching Advancement (CeLTA) and affiliated faculty of the Second Language Studies Program at Michigan State University. He is also research fellow at the Center for Language and Education (University of Leuven) where this study was conducted.

\section{ORCiD}

Kathelijne Jordens (D) http://orcid.org/0000-0002-7010-3668

\section{References}

Agirdag, Orhan, Kathelijne Jordens, and Mieke Van Houtte. 2014. "Speaking Turkish in Belgian Schools: Teacher Beliefs Versus Effective Consequences." Bilig - Journal of Social Sciences of the Turkish World 70: 7-28.

Agirdag, Orhan, Piet Van Avermaet, and Mieke Van Houtte. 2013. "School Segregation and Math Achievement: A MixedMethod Study on the Role of Self-fulfilling Prophecies." Teachers College Record 115 (3): 1-50.

Asker, Adel, and Marilyn Martin-Jones. 2013. "'A Classroom Is Not a Classroom If Students Are Talking to Me in Berber': Language Ideologies and Multilingual Resources in Secondary School English Classes in Libya." Language and Education 27 (4): 343-355. doi:10.1080/09500782.2013.788189.

Baker, Colin. 2011. Foundations of Bilingual Education and Bilingualism. 5th ed. Bristol: Multilingual Matters.

Belfi, Barbara, Carolien Moons, Jan Van Damme, Kris Van den Branden, Koen Van Gorp, and Machteld Verhelst. 2011. OBPWO Vorderingen van leerlingen voor taal (unpublished research report). Leuven: KU Leuven. 
Blackledge, Adrian, and Angela Creese. 2010. Multilingualism: A Critical Perspective. London: Bloomsbury Academic.

Bonacina, Florence, and Joseph Gafaranga. 2011. "Medium of Instruction' vs. 'Medium of Classroom Interaction': Language Choice in a French Complementary School Classroom in Scotland." International Journal of Bilingual Education and Bilingualism 14 (3): 319-334. doi:10.1080/13670050.2010.502222.

Creese, Angela, and Adrian Blackledge. 2010. "Translanguaging in the Bilingual Classroom: A Pedagogy for Learning and Teaching?" The Modern Language Journal 94 (1): 103-115. doi:10.1111/j.1540-4781.2009.00986.x.

Creese, Angela, and Adrian Blackledge. 2011. "Separate and Flexible Bilingualism in Complementary Schools: Multiple Language Practices in Interrelationship." Journal of Pragmatics 43 (5): 1196-1208. doi:10.1016/j.pragma.2010.10.006.

Creese, Angela, and Peter Martin. 2003. "Multilingual Classroom Ecologies: Inter-relationships, Interactions and Ideologies." Internationals Journal of Bilingual Education and Bilingualism 6 (3-4): 161-167. doi:10.1080/ 13670050308667778.

Creese, Angela. 2004. "Bilingual Teachers in Mainstream Secondary School Classrooms: Using Turkish for Curriculum Learning." International Journal of Bilingual Education and Bilingualism 7 (2-3): 189-203. doi:10.1080/ 13670050408667808.

Cruz-Ferreira, Madalena. 2010. Multilingual Norms. Frankfurt am Main: Peter Lang.

Cummins, Jim. 1979. Cognitive/Academic Language Proficiency, Linguistic Interdependence, the Optimum Age Question and Some Other Matters. Working Papers on Bilingualism, 19, 121-129.

Cummins, Jim. 2000. Language, Power, and Pedagogy: Bilingual Children in the Crossfire. Clevedon: Multilingual Matters.

Dooly, Melinda. 2007. "Constructing Differences: A Qualitative Analysis of Teachers' Perspectives on Linguistic and Cultural Diversity." Linguistics and Education 18 (2): 142-166. doi:10.1016/j.linged.2007.05.001.

Duarte, Joana. 2011. "Migrants' Educational Success Through Innovation: The Case of the Hamburg Bilingual Schools." International Review of Education 57 (5-6): 631-649. doi:10.1007/s11159-011-9251-7.

Ferguson, Gibson. 2003. "Classroom Codeswitching in Post-colonial Contexts: Functions, Attitudes and Policies." AlLA Review 16 (1): 38-51.

Ferguson, Gibson. 2009. "What next? Towards an Agenda for Classroom Codeswitching Research." International Journal of Bilingual Education and Bilingualism 12 (2): 231-241. doi:10.1080/13670050802153236.

García, Ofelia. 2011. Bilingual Education in the 21st Century: A Global Perspective. Oxford: John Wiley \& Sons.

Gogolin, Ingrid. 1997. "The 'Monolingual Habitus' as the Common Feature in Teaching in the Language of the Majority in Different Countries." Per Linguam 13 (2). http://perlinguam.journals.ac.za/pub/article/view/187.

Gort, Mileidis. 2012. "Code-Switching Patterns in the Writing-Related Talk of Young Emergent Bilinguals." Journal of Literacy Research 44 (1): 45-75. doi:10.1177/1086296X11431626.

Hélot, Christine, and Andrea Young. 2002. "Bilingualism and Language Education in French Primary Schools: Why and How Should Migrant Languages Be Valued?" International Journal of Bilingual Education and Bilingualism 5 (2): $96-$ 112. doi:10.1080/13670050208667749.

Hirtt, Nico, Ides Nicaise, and Dirk De Zutter. 2007. De school van de ongelijkheid. Berchem: Epo.

Hornberger, Nancy H. 2004. "The Continua of Biliteracy and the Bilingual Educator: Educational Linguistics in Practice." International Journal of Bilingual Education and Bilingualism 7 (2-3): 155-171. doi:10.1080/13670050408667806.

Jaspaert, Koen, and Griet Ramaut. 2000. "Don't Use English Words in Dutch: Portrait of a Multilingual Classroom in Flanders." In "Mann schreibt, wie mann spricht." Ergbenisse einer International-vergleichenden Fallstudieüber Unterricht in vielsrachingen Klassen, edited by Ingrid Gogolin and Sjaak Kroon, 27-40. Münster: Waxmann.

Jaspers, Jürgen. 2008. "Problematizing Ethnolects: Naming Linguistic Practices in an Antwerp Secondary School." International Journal of Bilingualism 12 (1-2): 85-103. doi:10.1177/13670069080120010601.

Jaspers, Jürgen. 2016. "Double-Edged Valorizations of Urban Heteroglossia." In The Multilingual Edge of Education, edited by Piet Van Avermaet, Stef Slembrouck, Koen Van Gorp, Sven Sierens, and Katrijn Maryns. Basingstoke: Palgrave.

Jørgensen, J. Normann. 2003. "Bilingualism in the Køge Project." International Journal of Bilingualism 7 (4): $333-352$. doi:10.1177/13670069030070040101.

Jørgensen, J. Normann. 2008. "Polylingual Languaging Around and among Children and Adolescents." International Journal of Multilingualism 5 (3): 161-176. doi:10.1080/14790710802387562.

Karrebæk, Martha Sif. 2003. "Iconicity and Structure in Codeswitching." International Journal of Bilingualism 7 (4): $407-441$. doi:10.1177/13670069030070040401.

Kroon, Sjaak, and Jan Sturm. 2000. "Comparative Case Study Research in Education." Zeitschrift Für Erziehungswissenschaft 3 (4): 559-576. doi:10.1007/s11618-000-0053-0.

Leman, Johan. 1997. "School as a Socialising and Corrective Force in Inter-ethnic Urban Relations." Journal of Multilingual and Multicultural Development 18 (2): 125-134. doi:10.1080/01434639708666308.

Lucas, Tamara, Ana María Villegas, and Margaret Freedson-Gonzalez. 2008. "Linguistically Responsive Teacher Education Preparing Classroom Teachers to Teach English Language Learners." Journal of Teacher Education 59 (4): $361-373$. doi:10.1177/0022487108322110.

Martin-Jones, Marilyn, and Mukul Saxena. 2003. "Bilingual Resources and 'Funds of Knowledge' for Teaching and Learning in Multi-ethnic Classrooms in Britain." International Journal of Bilingual Education and Bilingualism 6 (3-4): $267-282$. doi:10.1080/13670050308667785. 
Mitchell, C. 1984. "Case Studies." In Ethnographic Research: A Guide to General Conduct, edited by R. Ellen, $237-241$. London: Academic Press.

Møller, Janus Spindler, J. Normann Jørgensen, and Anne Holmen. 2012. "Polylingual Development among Turkish Speakers in a Danish Primary School - A Critical View on the Fourth Grade Slump." International Journal of Bilingual Education and Bilingualism 1-23. doi:10.1080/13670050.2012.735221.

Moodley, Visvaganthie. 2007. "Codeswitching in the Multilingual English First Language Classroom." International Journal of Bilingual Education and Bilingualism 10 (6): 707-722. doi:10.2167/beb403.0.

Moschkovich, Judit. 2007. “Using Two Languages When Learning Mathematics." Educational Studies in Mathematics 64 (2): 121-144.

Ncoko, S. O. S., R. Osman, and K. Cockcroft. 2000. "Codeswitching among Multilingual Learners in Primary Schools in South Africa: An Exploratory Study." International Journal of Bilingual Education and Bilingualism 3 (4): $225-241$. doi:10.1080/13670050008667709.

OECD (Organisation for Economic Co-operation and Development). 2006. Where Immigrant Students Succeed: $A$ Comparative Review of Performance and Engagement in PISA 2003. Paris: OECD.

OECD (Organisation for Economic Co-operation and Development). 2009. Top of the Class: High Performers in Science in PISA 2006. Paris: OECD.

Planas, Núria, and Mamokgethi Setati. 2009. "Bilingual Students Using Their Languages in the Learning of Mathematics." Mathematics Education Research Journal 21 (3): 36-59. doi:10.1007/BF03217552.

Probyn, Margie. 2009. "'Smuggling the Vernacular into the Classroom': Conflicts and Tensions in Classroom Codeswitching in Township/Rural Schools in South Africa." International Journal of Bilingual Education and Bilingualism 12 (2): 123-136. doi:10.1080/13670050802153137.

Pulinx, Reinhilde, Piet Van Avermaet, and Orhan Agirdag. 2015. "Silencing Linguistic Diversity: The Extent, the Determinants and Consequences of the Monolingual Beliefs of Flemish Teachers." International Journal of Bilingual Education and Bilingualism. Advance online publication. doi:10.1080/13670050.2015.1102860.

Reljić, Gabrijela, Dieter Ferring, and Romain Martin. 2015. "A Meta-analysis on the Effectiveness of Bilingual Programs in Europe." Review of Educational Research 85 (1): 92-128. doi:10.3102/0034654314548514.

Reyes, Iliana. 2004. "Functions of Code Switching in Schoolchildren's Conversations." Bilingual Research Journal 28 (1): $77-$ 98. doi:10.1080/15235882.2004.10162613.

Romaine, Suzanne. 1995. Bilingualism. Oxford: Wiley.

Sacks, Harvey, Emanuel A. Schegloff, and Gail Jefferson. 1974. "A Simplest Systematics for the Organization of Turn-taking for Conversation." Language 50 (4): 696-735. doi:10.2307/412243.

Sierens, Sven, and Piet Van Avermaet. 2014. "Language Diversity in Education: Evolving from Multilingual Education to Functional Multilingual Learning." In Managing Diversity in Education: Languages, Policies, Pedagogies, edited by David Little, Constant Leung, and Piet Van Avermaet, 204-222. Clevedon: Multilingual Matters.

Spotti, Massimiliano. 2008. "Exploring the Construction of Immigrant Minority Pupils' Identities in a Flemish Primary Classroom." Linguistics and Education 19 (1): 20-36. doi:10.1016/j.linged.2007.08.001.

Swain, Merrill, and Sharon Lapkin. 2000. "Task-Based Second Language Learning: The Uses of the First Language." Language Teaching Research 4 (3): 251-274. doi:10.1177/136216880000400304.

Van Der Wildt, Anouk, Piet Van Avermaet, and Mieke Van Houtte. 2015. "Multilingual School Population: Ensuring School Belonging by Tolerating Multilingualism." International Journal of Bilingual Education and Bilingualism. Advance online publication. doi:10.1080/13670050.2015.1125846.

Van Laere, Evelien, Koen Aesaert, and Johan van Braak. 2014. "The Role of Students' Home Language in Science Achievement: A Multilevel Approach." International Journal of Science Education 36 (16): 2772-2794. doi:10.1080/ 09500693.2014.936327.

Van Praag, Lore, Peter A. J. Stevens, and Mieke Van Houtte. 2015. "'No More Turkish Music!' The Acculturation Strategies of Teachers and Ethnic Minority Students in Flemish Schools." Journal of Ethnic and Migration Studies. doi:10.1080/ $1369183 X .2015 .1103171$.

Verhaeghe, Jean-Pierre, Heidi Knipprath, and Griet Mertens. 2007. Begrijpend lezen. Vierde leerjaar. Schoolfeedbackrapport n.a.v. deelname aan het PIRLS 2006-onderzoek. Leuven: Centrum voor Onderwijsefffectiviteit en Evaluatie.

Yagmur, Kutlay. 2009. "Language Use and Ethnolinguistic Vitality of Turkish Compared with the Dutch in the Netherlands." Journal of Multilingual and Multicultural Development 30 (3): 219-233. doi:10.1080/01434630802369445.

Young, Andrea S. 2014. “Unpacking Teachers' Language Ideologies: Attitudes, Beliefs, and Practiced Language Policies in Schools in Alsace, France." Language Awareness 23 (1-2): 157-171. doi:10.1080/09658416.2013.863902.

Zentella, Ana Celia. 1997. Growing up Bilingual: Puerto Rican Children in New York. Malden, MA: Blackwell. 